\title{
Special Editorial Note
}

eHealth Sri Lanka 2010,1(suppl.1):S1

DOI: http://dx.doi.org/10.4038/sljbmi.v1i0.3600

This supplemental issue contains the abstracts of oral and poster presentations of the free paper sessions of The eHealth Sri Lanka International Conference held at the Water's Edge Resort, Battaramulla, Sri Lanka, on the 15 and 16 September 2010.

The event was held under the auspices of The Health Informatics Society of Sri Lanka. The main theme of the Conference was "Towards IT enabled healthcare". The Conference was attended by 30 foreign delegates and 450 local participants. In addition to the abstracts of free paper and poster presentations printed in this issue, there were several Plenary Lectures, Guest Lectures and Symposia.

The Board of Reviewers for the abstracts printed in this issue consisted of Dr. B.J.C.Perera, Dr. Vajira H.W.Dissanayake, Professor Jayantha U. Weerasinghe and Dr. S.R.U.Wimalarathne. Review was undertaken following submission of the abstracts up to the submission deadline prior to the Conference.

Each oral platform presentation was allocated 15 minutes for presentation and 5 minutes for discussion following the presentation. The posters were displayed on both days for perusal by the participants and specific times were allocated for discussion with the authors at the site.

A printed copy of this Supplemental Issue was made available at the Conference. The current version is the electronic counterpart of the printed issue. It contains only the abstracts and the full papers were not included as the original printed version contained only the abstracts. The pagination of the electronic issue is different from the printed issue as it was thought that each abstract needed to have a single page for ease of documentation, future reference citing and proper indexing.

Dr. B.J.C.Perera

Editor-in-Chief

Sri Lanka Journal of Bio-Medical Informatics 